\title{
BUSTER KEATON Y EL SURREALISMO EN LA RESIDENCIA DE ESTUDIANTES. RAZONES DE UNA CONFLUENCIA
}

\author{
María del Carmen Molina Barea \\ Universidad de Córdoba
}

El objetivo del presente ensayo es indagar en la vinculación que existe entre el emblemático grupo de amigos de la Residencia de Estudiantes de Madrid -Luis Buñuel, Salvador Dalí y Federico García Lorcay el cine de Buster Keaton, proponiendo un análisis de motivos que expliquen dicha relación, así como su razón de ser en el contexto del naciente surrealismo español.

Palabras clave: Buster Keaton; Surrealismo; Buñuel; Dalí; Lorca; Residencia de Estudiantes.

\section{BUSTER KEATON AND SURREALISM IN THE RESIDENCIA DE ESTUDIANTES: REASONS FOR CONVERGENCE}

The aim of this essay is to investigate the connections between the emblematic group of friends at the Madrid Residencia de Estudiantes -Luis Buñuel, Salvador Dalí, Federico García Lorca-and the cinema of Buster Keaton, analyzing the motives for this relation, as well as its meaning within the context of nascent Spanish Surrealism.

Key words: Buster Keaton; Surrealism; Buñuel; Dalí; Lorca; Residencia de Estudiantes.

\section{Introducción}

No son pocas las ocasiones en que se ha aludido a Buster Keaton desde la óptica surrealista. La posibilidad de una vinculación entre el "gran Cara de Palo" y el espíritu de ese movimiento artístico -y vital- que se dio en llamar surrealismo ha sido intuida por muchos estudiosos, pero lo cierto es que escasamente ha merecido una atención detallada o exclusiva. A pesar de ello, a lo largo de la escuálida bibliografía sobre el tema, un principal axioma ha llegado a hacerse evidente: hablar de Buster Keaton en su conexión con el surrealismo equivale en buena medida a referirse a tres personalidades muy concretas. Se trata de Luis Buñuel, Salvador Dalí y Federico García Lorca; si bien el listado podría ampliarse con otros nombres de la Generación del 27 y del círculo juvenil de la madrileña Residencia de Estudiantes, lugar de encuentro de los tres artistas anteriormente mencionados y punto de partida de su prolífica amistad ${ }^{1}$.

\footnotetext{
${ }^{1}$ Luis Buñuel sería el primero de los tres en llegar a la Residencia de Estudiantes, en el año 1917, y permanecería allí hasta 1925. Le sigue Lorca, residente entre los años 1919 y 1925. El último en incorporarse es Dalí, que se aloja en la Residencia entre 1922 y 1926.
} 
Así pues, no hay biografía lorquiana, ni contribución en torno al cine buñueliano, o estudio acerca del joven Dalí, en que no se haga mención al nombre de Buster Keaton. Ocurre, sin embargo, que esta alusión queda con frecuencia reducida a una indicación por la cual se señala la afición del trío de amigos de la "Resi" (como así llamaban los residentes a la Residencia de Estudiantes) por la figura y cine de Keaton, y en la que, a más pedir, se sugiere el carácter poético e irracional del cineasta como principal motivo de interés por parte de estos jóvenes creadores, promotores indudables de las propuestas surrealistas en territorio español. Esto es lo que ocurre por ejemplo en las investigaciones de Uta Felten y C. Brian Morris -a pesar de todo, pioneras y referenciales-, así como en las variadas fuentes bibliográficas que se hacen eco de la conexión de Keaton y estos tres referidos artistas, manteniéndose por lo general ajenas a un estudio pormenorizado de las razones más íntimas que justifican dicha relación.

En consecuencia, lo que se persigue en estas páginas es desglosar el abanico de aspectos que sustenta el engarzado "Keaton-Buñuel-Dalí-Lorca"; lo que de forma más precisa puede calificarse de hermanamiento "Buster Keaton-surrealismo" o, más específicamente, "Buster Keaton-surrealismo español", y que se concreta, de manera icónica, en el dualismo "Buster Keaton-Residencia de Estudiantes", en el sentido de que tal binomio resume, y asume de forma ejemplar, las circunstancias personales y coyunturales de trascendencia contextual, artística, e incluso iconográfica, que explicitan la bienvenida de Buster Keaton entre las filas del surrealismo español. En definitiva, el objetivo del presente trabajo es proponer las pautas para una mejor comprensión de las razones que hicieron que personalidades como Buñuel, Lorca o Dalí, así como otros compañeros "residenciales", prestaran una significativa atención y dirigieran especial admiración hacia ese irrepetible artista de 'ojos admirables' ${ }^{\prime 2}$ y emblemático sombrerito porkpie.

\section{Buster Keaton y la Residencia de Estudiantes}

Madrid, años veinte. La capital española va recibiendo el influjo del nuevo y atrayente fenómeno de entretenimiento: el cinematógrafo. Comienzan, pues, a abrirse numerosas salas dedicadas a tal fin. Pero también son muchos los que contemplan el nuevo medio como una poderosa vía de expresión artística. En este sentido destaca la labor del Cineclub Español, fundado en 1928 por Ernesto Giménez Caballero, así como las sesiones cinéfilas organizadas por Luis Buñuel en la Residencia de Estudiantes entre 1927 y 1928 bajo el auspicio de la Sociedad de Cursos y Conferencias.

En este ambiente, las películas de Charlie Chaplin, Harold Lloyd y las de nuestro apreciado Pamplinas (como también se conoció a Buster Keaton en España) comienzan a colonizar el imaginario del público español. Los jóvenes que en estos años se alojan en la Residencia de Estudiantes de Madrid no serán ajenos a semejante actividad cinéfila. Por el contrario, ir al cine se convirtió en una de las principales prácticas entre los residentes. Así lo recuerda Buñuel:

Durante aquellos días se abrían en Madrid nuevos cines, que atraían a un público cada vez más asiduo. Íbamos al cine unas veces con alguna novia, para poder arrimarnos a ella en la oscuridad, y entonces cualquier película era buena, y otras, con los amigos de la Residencia. En este último caso preferíamos las películas cómicas norteamericanas, que nos encantaban: Ben Turpin, Harold Lloyd, Buster Keaton, todos los cómicos del equipo de Mack Sennett. El que menos nos gustaba era Chaplin³.

\footnotetext{
${ }^{2}$ Erébe en Oliver, Garner, (comp.), 1972: 26.

${ }^{3}$ BuÑuel, 1982:76.
} 
De hecho, Keaton llegaría a convertirse en el más apreciado por los amigos de la Residencia. En palabras de Gibson, "Dalí y Lorca, como Rafael Alberti y otros amigos más o menos relacionados con la Residencia de Estudiantes, son férvidos cinéfilos y apasionados admiradores de Buster Keaton"4. Sirva como ejemplo una carta de Dalí a Lorca fechada en 1925, en la que el pintor le comenta a su amigo: "Parece que Buster Kiton [sic] ha hecho una película en el fondo del mar con su sombrerito de paja encima de la escafandra de buzo"s. Se trata de The Navigator (El Navegante), rodada en 1924 y estrenada en Madrid, en los cines Goya y Gravina, el 23 de diciembre de 1925. En otra carta de 1925 a Lorca, Dalí incluye un collage que titula El casamiento de Buster Keaton, que realiza con dibujos astronómicos, fotografías de Keaton y recortes de prensa sobre el compromiso matrimonial del actor con Natalie Talmadge. Estas anécdotas dan evidentes muestras del atento seguimiento de Buster Keaton por parte de Dalí y sus compañeros más allegados de la Residencia en estas fechas.

Queda por tanto evidenciado un panorama de contacto directo entre Keaton y los surrealistas de la Residencia de Estudiantes, que son, en otras palabras, los representantes -más bien, fundadores- del surrealismo en suelo español. Y es que tal concomitancia no es pura casuística: la Residencia de Estudiantes se erige sin duda en la matriz generadora del surrealismo en España. En ella confluyen las personas e inspiraciones artísticas oportunas para dar lugar al escenario detonante del surrealismo en territorio nacional. Un surrealismo que manifiesta unos rasgos muy concretos, y que no siempre concuerda con los postulados estéticos del grupo parisino. No en vano, Rafael Santos Torroella proponía que "tal vez fuera oportuno replantearse la cuestión tantas veces abordada de la posible existencia de un surrealismo específicamente español o derivado del movimiento del mismo nombre fundado en París, en 1924" "En efecto, el surrealismo español es una rama con carácter propio, que en buena medida fundamenta sus cimientos en el ambiente formativo y vivencial de estos jóvenes creadores durante sus años "residenciales". En este contexto es obligado mencionar el entrañable nombre del residente José -Pepín- Bello Lasierra, cuyo natural surrealismo serviría de espontáneo canalizador y fuente de inspiración para el florecimiento de la atmósfera surrealista en la Residencia, influyendo poderosamente en Buñuel, Dalí y Lorca. No ha de extrañarnos, pues, que Santos Torroella hablara de la posibilidad de referirse a un "estilo y estética residencial".

Veamos, pues, a continuación, cómo se inserta en este ambiente el cómico de la "bella mirada triste"

\section{Buster Keaton, poesía contra lo putrefacto}

Nacido como Joseph Francis Keaton, la anécdota le bautizó desde la infancia con el nombre de "Buster", pero el mundo le conoció también con otros apelativos, que solían responder a la sobria expresión que tanto llegó a identificarle. "The Great Stone Face" fue su etiqueta anglosajona; "Frigo", por sus frías maneras, se le llamó en Francia... Esta comedida expresividad de Keaton, "tan modesta como la de una botella" ${ }^{8}$, fascinó al trío de la Residencia. Buñuel la calificó de "desinfección sentimental", y Dalí, de "poesía pura". Pero, ¿a qué es debida tal fascinación? Dicho brevemente, la "expresión monocorde" de Keaton" representaba el baluarte perfecto en la batalla

\footnotetext{
${ }^{4}$ Gibson, 2000: 138.

${ }^{5}$ GibSON, 2000: 139.

${ }^{6}$ Santos Torroella, 1992: 10.

${ }^{7}$ Erébe en Oliver, Garner, (comp.), 1972: 15.

${ }^{8}$ Buñuel en Oliver, Garner, (comp.), 1972: 34.

${ }^{9}$ Contraria por excelencia a la de un 'infinitesimal Jannings'. Buñuel en Oliver, Garner, (comp.), 1972: 33.
} 
que el grupo de amigos había entablado contra lo "putrefacto"; noción que, condensada en la imagen de un burro muerto, acuñaron para referirse a aquellas manifestaciones artísticas y personales impregnadas de una sensiblería y retórica tradicional, muy en línea de la herencia juanramoniana, a la que por supuesto, se oponía el espíritu surrealista ${ }^{10}$.

El impasible rostro de Keaton iba pues ligado a un sentimiento de sobriedad emotiva y al convencimiento de una liberación de la tradición y de los valores arcaizantes de la cultura europea. En este sentido habla también Dalí del cine de Keaton como cine "anti-artístico", el cual se contrapone al cine de inclinaciones sentimentaloides y afán trascendentalista ${ }^{11}$. No sorprende entonces que Buñuel, acerca de Un chien andalou, el mítico film de 1929 que realiza con Dalí, exprese lo siguiente:

En UN PERRO ANDALUZ se sitúa por primera vez el cineasta en un plano poético-moral. (Léase moral en el sentido de la que rige los sueños o las compulsiones parapáticas). [...] Por eso resulta un film voluntariamente anti-plástico[,] anti-artístico según los cánones tradicionales. [...] Las fuentes en las que se inspira el film son las de la poesía, liberada del lastre de la razón[,] de la tradición [y de la moral] ${ }^{12}$.

Esta voluntad "anti-putrefacta" se personifica en Keaton gracias a la puesta en escena de un alejamiento empático respecto al espectador, logrado por medio de esa estoica expresión y maneras desprovistas de romanticismo. Así, mientras el resto de cómicos sonreían o guiñaban un ojo a la cámara en el intento de incorporar al espectador como compañero de aventuras, Keaton desarrollaba un aire de extrañamiento que separaba ambas esferas... y con una clara intencionalidad:

A menudo me han preguntado por qué mantengo uniformemente, a lo largo de mis películas, esta cara tan desolada. Creo que es bien sencillo; desde mis comienzos en el music-hall observé que, cuando se hace algo más o menos divertido, se provoca en el auditorio una carcajada mucho mayor si se permanece indiferente y luego asombrado por la hilaridad del público. Por el contrario, hay cómicos que parece que se colocan siempre de parte del público y le hacen participar de sus confidencias. Así procedía Fatty; de esta forma, el público se reía con él, mientras que en mi caso el público se ríe de mín $^{13}$.

Casi a lo Bertolt Brecht, Buster Keaton no buscaba favorecer la identificación situacional o emocional del espectador. Su humor se basaba precisamente en lo contrario. El espectador es el que observa lo que le acontece al personaje de Buster y se ríe de él y de cómo éste encaja la situación. Por eso declaraba el cineasta: "Cuanto más serio me ponía, mayores eran las carcajadas que provocaba"14 (fig. 1).

Pero Keaton no se limitaba sólo a borrar la risa de su repertorio facial, sino que desplegaba un automatismo gestual y un aire onírico de frías maneras. Discreto, despreocupado, es un tém-

${ }^{10}$ Resulta fuertemente ilustrativa la sucinta carta que Buñuel y Dalí envían al poeta de Moguer expresando su opinión sobre Platero y yo, obra a la que dedican un contundente “ißMERDE!!”. (RAmírEZ, 2002: 29).

11 'Artística, horrible palabra que solamente sirve para indicar que las cosas carecen de arte en absoluto. Espectáculo artístico, fotografía artística, anuncio artístico, mueble artístico. ¡Horror! ¡Horror! Todos estamos de acuerdo con el objeto puramente industrial, el dancing y la poesía quintaesenciada del sombrerillo de Buster Keaton.' (Dalí en MinguET, 2008: 58); opinión que el artista recoge también en su artículo Film-arte, film-antiartístico, publicado en La Gaceta Literaria en diciembre de 1927.

12 Buñuel en Hernández Pin, Sánchez, (coord.), 2009: 31.

13 Keaton, 2006: 47-8.

${ }^{14}$ Keaton en Oliver, Garner, (comp.), 1972: 65. 
pano de poesía irracional, un ser casi transparente. Todo esto maravillaba a Buñuel: "Asepsia. Desinfección. Liberadas de la tradición, nuestras miradas se rejuvenecen en el mundo juvenil y temperado de Buster, gran especialista contra toda desinfección sentimental" ${ }^{\prime 15}$. Keaton es la infancia libre, sin remordimientos ni dobleces. Es amoral, que no inmoral, como sí frecuentemente lo es el vagabundo de Chaplin. Buster Keaton es, en definitiva, aquel niño, de imaginación y asombro sin límites, que como expresara André Breton en el manifiesto surrealista de 1924, comienza el día sin el peso de la tradición o las normas, sin las tribulaciones del adulto. Es una brisa fresca, ecuánime, desinfectada. Al contrario que un Charlot sublimado en el almíbar de El chico, "Buster jamás intentará hacernos llorar" $" 16$

Por otro lado, la manida comparación entre Chaplin y Keaton adquiere en el contexto surrealista un cariz especial si tenemos en cuenta que los jóvenes de la Residencia atacaban a Chaplin mientras ensalzaban a Keaton ${ }^{17}$. En una entrevista que le hace Dalí para L'Amic de les Arts en 1929, Buñuel da las claves de esta disyuntiva:

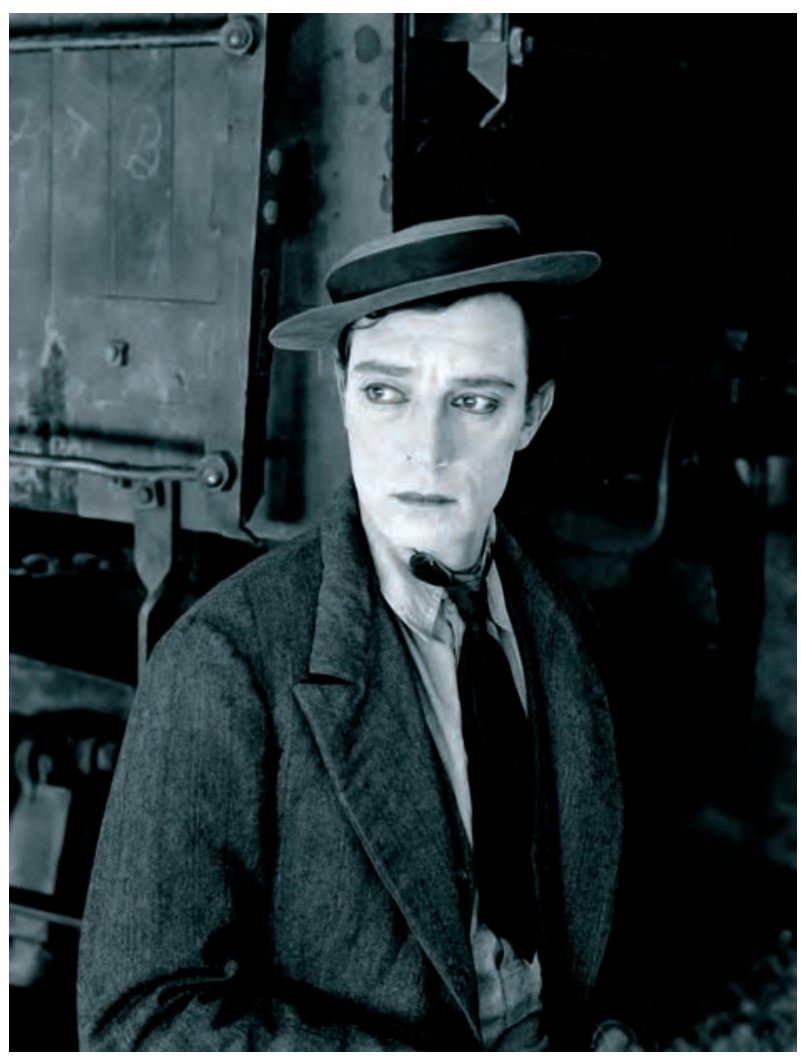

Fig. 1. La "expresión monocorde" de Keaton.

Fotograma de Go West (El rey de los cowboys, 1925).

Aún hay algún viejo putrefacto, que se mantiene puro y habla del "corazón amable de Charlot". [Chaplin] Ha desertado del bando de los niños y ahora se dirige a los artistas e intelectuales. Pero en recuerdo de los tiempos en que no pretendía ser más que un payaso, tengamos para él un piadoso merde. Y no volvamos ya nunca a verle ${ }^{18}$.

Estas declaraciones guardan una asombrosa similitud con la opinión que muchas décadas después plasmaría el propio Keaton en sus memorias:

Me temo que la avalancha de elogios a su brillante dirección trastornaron a Charlie. Su desgracia fue creerse lo que los críticos escribieron sobre él. Dijeron que era un genio,

${ }^{15}$ Buñuel en Oliver, Garner, (comp.), 1972: 33

16 Buñuel en Oliver, Garner, (comp.), 1972: 33

${ }^{17}$ Por el contrario, los surrealistas parisinos demostraron mayor interés en Chaplin que en Keaton; como también los dadaístas, antepasados inmediatos del surrealismo, que adoraron el absurdo de Charlot y mostraron abiertamente sus simpatías hacia él en varias ocasiones. El surrealismo parisino, menos tajante que el español y más inclinado a la dinámica de lo arbitrario (y por tanto más en consonancia con la herencia dadá), no supo apreciar que el de Keaton es claramente un espíritu surrealista. Por ejemplo, en el Diccionario abreviado del surrealismo Breton incluye una entrada para Chaplin, pero no para Keaton. Sin embargo, Buster Keaton va más allá del nihilismo dadaísta, el cual sí se adecua más a la filosofía actitudinal de Charlot. Definitivamente, Buster era el alma gemela de las preocupaciones del surrealismo español.

18 SÁNCHEZ VidAL, 2009: 158 
cosa que yo sería el último en negar, y a partir de entonces, Charlie Chaplin, el payaso divino, intentó comportarse, pensar y hablar como un intelectual ${ }^{19}$.

Tal coincidencia sirve para manifestar la íntima conexión que unía los modos de entender lo artístico de Luis Buñuel y Buster Keaton; a lo que se suma también Dalí, quien expresará reveladoramente las razones de su "keatonmanía" en la que es la obra más significativa del Dalí poeta, San Sebastián, compuesta en 1927 y dedicada a García Lorca:

Buster Keaton -ịhe ahí la poesía pura, Paul Valéry!-. Avenidas post-maquinistas, Florida, Corbusier, Los Ángeles, Pulcritud y euritmia del útil estandarizado, espectáculos asépticos, anti-artísticos, claridades concretas, humildes, vivas, alegres, reconfortantes, para oponer al arte sublime, delicuescente, amargo, putrefacto... ${ }^{20}$.

\section{La situación surrealista: lo cómico, lo onírico y el sueño}

Cuenta Gabriel Celaya que cuando Lorca y Dalí compartían habitación en la Residencia de Estudiantes discutían con frecuencia, y que en tales ocasiones ponían en práctica un singular método de convivencia: "Llenaban el cuarto de arena y hacían caminitos individuales desde la puerta a la cama, desde la cama al lavabo, y ponían macetas con flores en los bordes y en el cruce para andar sin rozarse ni hablarse" ${ }^{21}$. Semejante espectáculo merece sin duda ser calificado de situación surrealista. Tampoco lo es menos aquella ocasión en que ambos amigos convirtieron su habitación en una imaginaria balsa de Medusa a la deriva, sacando los brazos por la ventana y pidiendo auxilio. De hecho, eran numerosas las ocurrencias de este tipo entre los amigos de la Residencia; todas ellas impregnadas de una comicidad irreal, una imaginación y una mecánica poética muy semejantes a las que se aprecian en los films de Keaton, que por extensión, se hallan plagados de situaciones surrealistas. En este sentido se entiende por ejemplo que Buster, sentado a la mesa de un restaurante, decida afeitarse tras observar los continuos retoques de maquillaje de su acompañante femenina (The Three Ages -Las Tres Edades-, 1923) ${ }^{22}$, o que sumergiéndose en el mar con un rifle, salga después llevando en la otra mano un pez de aceptables dimensiones (The Love Nest -Pamplinas, lobo de mar-, 1923) ${ }^{23}$, o que abra la puerta de un coche de cuatro plazas para dejar salir a una tropa interminable de soldados (Moonshine -Fatty y las estrellas-, 1918) (fig. 2).

Más allá de la deformación que el uso cotidiano haya podido ejercer en el vocablo, una situación surrealista es propiamente aquella que se rige por lo que André Breton definió como la unión misteriosa de realidad e irrealidad, como la simbiosis acción-sueño: "Creo en la futura armonización de estos dos estados, aparentemente tan contradictorios, que son el sueño y la realidad, en una especie de realidad absoluta, en una sobrerrealidad o surrealidad, si así se puede llamar"24. No cabe duda de que Buster Keaton consigue este objetivo de forma excepcional. El ambiente que se respira en sus películas es de una incuestionable surrealidad: los gags que el cineasta propicia -que responden a una lógica interna, cómica, misteriosa; propia de una poética opuesta a la lógica habitual. En definitiva, una poética surrealista-, hace confluir sutilmente lo real con lo irreal. Así mismo, al no identificarse el protagonista con el público y al producir ese aire de alie-

\footnotetext{
${ }^{19}$ KeAton, 2006: 304.

${ }^{20}$ Gibson, 2000: 193

${ }^{21}$ Sánchez Vidal, 2009: 85.

22 Película que se estrenó en Madrid en marzo de 1925.

${ }^{23}$ Película estrenada en Madrid el 2 de noviembre de 1924 en las salas Real Cinema y Príncipe Alfonso.

${ }^{24}$ BReton, 2002: 24.
} 
nación, las situaciones de Keaton inspiran la sensación de estar viviendo un sueño, como ocurre por ejemplo en el magistral corto The boat (La barca, 1921), constituido de principio a fin por situaciones surrealistas e impregnado de una fuerte carga onírica.

Películas como The Love Nest y The Playhouse (El gran espectáculo, 1921) son otros títulos que dan testimonio de este fenómeno. Títulos en los que además se suma un significativo elemento: el sueño. Y es que el recurso al sueño fue una herramienta empleada en varias ocasiones por Buster Keaton, al brindarle el contexto propicio para enmarcar a su personaje y desarrollar sus pe-

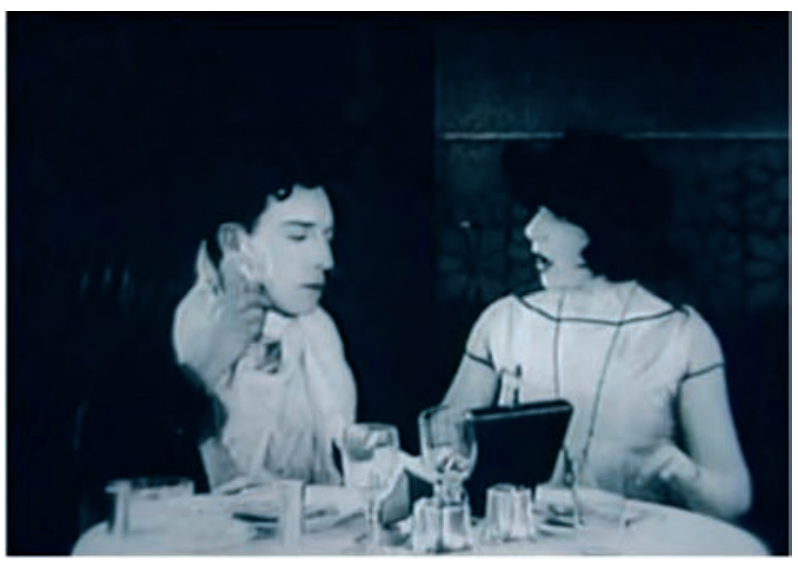

Fig. 2. Buster se afeita en un restaurante. Escena de The Three Ages (Las tres edades, 1923). ripecias, como ocurre en Convict 13 (Pamplinas presidiario, 1920) ${ }^{25}$, The Haunted House (Pamplinas y los fantasmas, 1921) ${ }^{26}$, The Frozen North (Pamplinas en el Polo Norte, 1922) ${ }^{27}$, y por excelencia, en el genial Sherlock Jr (El moderno Sherlock Holmes, 1924) ${ }^{28}$. El empleo del sueño en el argumento y construcción cinematográficos lo aprendió Keaton de Roscoe -Fatty-Arbuckle, el cómico al que debió su entrada en el mundo del cine, y con quien trabajó durante varios años entablando una sólida amistad. En concreto, Fatty emplea el sueño en el corto Goodnight, nurse! (;Buenas noches, enfermera!, 1918), que narra una historia que ocurre en sueños. Keaton toma esta idea, pero la desarrolla de forma personal, elevándola a la máxima potencia. Esta natural predisposición de Keaton hacia los sueños es un rasgo más que lo vincula al ambiente surrealista, cuyos representantes tanto admiraron el poder de los sueños descubierto por Freud. Como confiesa Buñuel, "esta locura por los sueños, por el placer de soñar, que nunca he tratado de explicar, es una de las inclinaciones profundas que me han acercado al surrealismo" 29 .

Por lo tanto, en Buster Keaton no podemos hablar de realidad, sino de surrealidad. Notemos de nuevo la contraposición con el cine de Chaplin: las de Charlot son situaciones "de realidad", en las que acontecen gags más o menos graciosos, pero siempre dentro de los límites de la realidad habitual, diurna, si se quiere. Keaton se mueve en el subterfugio onírico; su realidad está bañada de un aura subconsciente, casi sonámbula, como la que habita los poemas lorquianos... Buster no es por tanto un marginado de la sociedad, como el vagabundo Charlot, sino que es un marginado de la realidad; alguien que sólo entabla contacto con el entorno, personas, y objetos al desplegar un sistema propiamente surrealista. Con su cine, con su "poesía pura", Keaton hace posible el poder del sueño en estado vigil ${ }^{30}$; en definitiva, lo que los surrealistas pretendían. Digámoslo claro: Buster Keaton era un poeta surrealista. No en vano opinaba Dalí

${ }^{25}$ Película estrenada en el Real Cinema de Madrid el 20 de diciembre de 1925.

${ }^{26}$ Película que se estrenó el 19 de noviembre de 1925 en el Real Cinema de Madrid.

${ }^{27}$ Película estrenada en Madrid el 11 de noviembre de 1924 en las salas Real Cinema y Príncipe Alfonso

${ }^{28}$ Película que se estrenó en Madrid en octubre de 1925.

${ }^{29}$ BUÑUEL, 1982: 92.

${ }^{30}$ En opinión del Premio Nobel de Literatura Tomas Tranströmer, 'la poesía es algo parecido a un sueño en la vigilia.' (En entrevista al diario EL PAIS, 7 de Octubre de 2011). 
que los verdaderos poetas, entre los que situaba a Keaton, eran aquellos que pintaban o hacían cine ("There are no poets who write. The best paint or make film. Buster, Harry Langdon"'31), y Buñuel defendía el cine como instrumento de poesía y el mejor medio para expresar el mundo de los sueños. Así pues, y parafraseando a René Crevel, podríamos afirmar que con Keaton 'la vigilia ha dejado de ridiculizar al sueño ${ }^{32}$ Buster Keaton... "iQué subconsciente hecho sensible $[\ldots] !{ }^{\prime 33}$.

\section{El-múltiple-objeto surrealista}

En una situación surrealista el modo de dialogar con el entorno viene regido por la intuición poética, que induce a contactar con la realidad y sus objetos de un modo muy particular, y de consecuencias productivas. Breton lo explica así en El surrealismo en sus obras vivas:

Para realizar esto último [investigar la realidad en torno], el mejor medio de que el hombre dispone es la intuición poética. Esta, liberada al fin por el surrealismo, no solamente tiene el poder de asimilar todas las formas conocidas, sino que también es audaz creadora de nuevas formas, por lo que se halla en situación de aprehender todas las estructuras de nuestro mundo, manifiestas o $\mathrm{no}^{34}$.

De este modo, la relación de un sujeto surrealista, como es el personaje de Keaton, con aquello que le circunda, cristalizará en la creación de objetos extraños, originales; posibles únicamente al margen de la lógica habitual. De hecho, Buster Keaton está muy lejos del utilitarismo convencional. $\mathrm{Su}$ imaginativa visión le hace transformar los objetos que le rodean en lo que podríamos llamar "objetos surrealistas", o más bien "objetos oníricos"; es decir, "ciertos objetos que sólo se perciben en sueños" $"$. Es por eso que suelen ser objetos novedosos, raros e irreales. En opinión de Puelles Romero, "los artefactos de resistencia a la definición que son los objetos surrealistas se caracterizan por diversos atributos, entre los cuales se hallan los que los hacen ser: 1) Inesperados, 2) ininteligibles, 3) inidentificables y 4) inexplicables" ${ }^{\prime 36}$.

Pero, ¿cómo surge un objeto surrealista? Según indica Breton, un objeto surrealista nace del procedimiento, desarrollado tanto por pintores como por poetas, consistente

en la explotación del encuentro fortuito, en un plano adecuado, de dos realidades distantes (lo cual no es más que paráfrasis y generalización de la célebre frase de Lautréamont: Bello como el fortuito encuentro, en una mesa de disección, de una máquina de coser y un paraguas), o, para servirnos de una frase más breve, el cultivo de los efectos de un extrañamiento sistemático... ${ }^{37}$.

La conocida imagen extraída de Los Cantos de Maldoror reúne ejemplarmente la clave de la constitución del objeto surrealista: la poética extrañeza de un nuevo objeto formado por la unión de varios objetos ajenos entre sí. Pues bien, Keaton es un magnífico mediador entre objetos dispares, y así, de acuerdo con una innata intuición poética, concibe objetos puramente imaginativos,

\footnotetext{
31 GaLe, 2007: 17.

32 Breton, Eluard, 2003: 95.

33 Erébe en Oliver, Garner, (comp.), 1972: 20.

34 BRETON, 2002: 222.

35 Breton, Eluard, 2003: 71.

36 Puelles Romero, 2002: 25.

37 BReton, 2002: 202.
} 
puramente inverosímiles, puramente surrealistas. Para ello se vale de diversos mecanismos, apreciables a lo largo de su filmografía, entre los que destacaremos dos:

1) La creación del nuevo objeto resulta de la síntesis aleatoria de varios objetos dispares. Esta dinámica se aprecia en Cops (La mudanza, 1922), donde Buster fusiona una percha plegable con un guante de boxeo, y un teléfono con unos auriculares, o en The Scarecrow (El espantapájaros, 1920), plagado de electrodomésticos "simbióticos" como un horno-tocadiscos, un frigorífico-librería, y una bañera-sofá.

2) El nuevo objeto surge al alterar progresivamente el carácter de un objeto preexistente. Con este método Keaton demuestra su extraordinaria visión surrealista, por la cual sabe extraer funciones y apariencias distintas de un mismo objeto, adecuándolo a las demandas cómicas de la situación. Es característico el caso en el que Buster usa un palo de golf que luego emplea como palo de billar, después como un remo, y que finalmente aplica como timón de una barca (Convict 13); o aquel en el que se emociona con la canción de un guitarrista para después calzarse los instrumentos como raquetas para andar sobre la nieve, y quitárselas luego para golpear las bolas de nieve que le arrojan, sugiriendo la imagen de un "surrealista" jugador de tenis (The Frozen North).

El primero de los sistemas coincide claramente con los preceptos inspirados en Lautréamont, y de forma específica recuerda a los recursos sintéticos desarrollados por Dalí al crear objetos surrealistas como Busto femenino retrospectivo (1933), y Teléfono-bogavante (1936). Pero quizá el método más interesante sea el segundo. Según éste, el objeto es sometido a una metamorfosis paulatina por la que Keaton se encarga de mostrarnos un objeto que, aunque es uno, es múltiple a la vez. Un objeto que, por así decirlo, contiene a su vez varios objetos en potencia, y que depende de la mirada del usuario para efectuar su conversión. Breton alude a esta intención de la mirada que determina diferentes formas en una misma forma en relación a la técnica del frottage, que los surrealistas toman del consejo de Leonardo a sus discípulos de hallar inspiración en las formas de una mancha en un muro o de una nube en el cielo ${ }^{38}$. Muy ligado a estas ideas aparece el sistema paranoico-crítico de Salvador Dalí, que aplica por primera vez en El hombre invisible (1929), y perfecciona en cuadros como El enigma sin fin (1938) y Mercado de esclavos con aparición del busto invisible de Voltaire (1940). El propio Dalí explica así su método:

Sobre la base de un procedimiento netamente paranoico ha sido posible obtener una imagen doble, es decir, la representación de un objeto que, sin la mínima modificación figurativa o anatómica, sea al mismo tiempo la representación de otro objeto absolutamente distinto [...]. La obtención de una tal imagen doble ha sido posible gracias a la violencia del pensamiento paranoico, que se ha servido con astucia y habilidad de la cantidad necesaria de pretextos, coincidencias, etc., aprovechándolos para hacer aparecer la segunda imagen que, en este caso, ocupa el lugar de la idea obsesiva. La imagen doble, cuyo ejemplo puede ser el de la imagen de un caballo que, al mismo tiempo, es la imagen de una mujer, puede prolongarse, continuando el proceso paranoico, siendo entonces suficiente la existencia de otra idea obsesiva para que aparezca una tercera imagen (la imagen de un león, por ejemplo), y así sucesivamente $[\ldots]^{39}$.

Dicha técnica se conoce también como "imagen múltiple", dada la posibilidad de sugerir distintas formas simultáneamente dependiendo de la percepción. De hecho, este sistema implica "una

\footnotetext{
38 BRETON, 2000: 98-9.

39 Dalí en Poyato SÁnchez, 2006: 153.
} 
correspondiente multiplicidad de lecturas por parte del espectador"40; afirmación que podría ser igualmente aplicada a las situaciones de Buster Keaton. Dalí proporciona otra definición de su método, que sería perfecta para calificar el de Keaton: "Método espontáneo de conocimiento irracional basado en la objetivación crítica y sistemática de las asociaciones e interpretaciones delirantes ${ }^{\text {"41 }}$. En efecto, tanto Dalí como Keaton buscan un método espontáneo e irracional basado en asociaciones delirantes; una dinámica que es intrínsecamente surrealista: "El surrealismo se basa en la creencia en la realidad superior de ciertas formas de asociación desdeñadas hasta la aparición del mismo, y en el libre ejercicio del pensamiento"42. Algo que no por casualidad ocurre también en el mundo de los sueños, especialmente en el proceso de elaboración onírica efectuada por condensación; lo que en palabras de Freud es calificado como la "tendencia a formar nuevas unidades con elementos que en el pensamiento vigil seguramente habríamos mantenido separados" ${ }^{43}$.

Podríamos decir entonces que el surrealismo se hace presente en la unión de elementos ajenos entre sí que sólo en los sueños (o en las situaciones de Keaton...) pueden verse asociados. En resumen, Buster Keaton es inseparable de los objetos y del uso surrealista que a éstos les da. Su universo está plagado de objetos, y él convive feliz con ellos, para orgullo de Buñuel, que alaba el hecho de que "Keaton llegue a la comicidad por la armonía directa con los utensilios, las situaciones y los demás elementos de la realización" $"$.

\section{Fetichismo: blanduras y fragmentaciones}

Es bien conocida la deuda que el surrealismo mantiene para con Freud. El poder liberador del sueño, la vida del subconsciente y una novedosa revisión de lo sexual son elementos clave en el particular universo surrealista, cuyos representantes hallaron en Freud las herramientas perfectas para encauzar sus deseos revolucionarios. El surrealismo de la "Resi" tampoco fue ajeno a la oleada freudiana. Dalí y Buñuel eran apasionados lectores de Freud, y a estas alturas no cabe cuestionar la indudable huella que las teorías del maestro del psicoanálisis dejaron en las obras tanto del pintor como del cineasta. Las obsesiones edipales y narcisistas marcaron al joven Dalí, y la violencia de la erótica fetichista al contundente Buñuel. Uno y otro supieron reinterpretar el erotismo y el fetichismo en sus creaciones, y muy probablemente supieron también apreciar el surco de estos mismos elementos en la producción fílmica de su admirado Buster Keaton.

La primera pauta para dilucidar esto la proporciona el método paranoico-crítico, que nos introduce en el fetichismo daliniano de manos de la imagen "caballo-mujer-león", que el propio artista usara para definir su sistema pictórico, y que conviene no pasar por alto, dada la importancia que adquiere por sus valores fetichistas. Este caballo "múltiple" aparecía ya en la primera formulación del sistema paranoico-crítico: en el fondo de El hombre invisible, cuadro que Dalí calificó como su "fetiche paranoico" 45 . Dicha imagen irá adquiriendo mayor protagonismo y reiterándose en obras como Mujer invisible dormida, caballo y león (1930), y en el film Cinco minutos a propósito del surrealismo (1930-1). Pero el interés obsesivo de este motivo en Dalí no se explica sólo por la posibilidad de favorecer una multiplicidad de formas y percepciones; en realidad debe mucho más a su factura de aspecto blando y a un sentido de deformación de la materia. Esto no debe sor-

\footnotetext{
${ }^{40}$ RAMírez, 2002: 130.

${ }^{41}$ Breton, Eluard, 2003: 76.

42 Breton, 2002: 34.

${ }^{43}$ FREUd, 1966: 42.

${ }^{44}$ Buñuel en Oliver, Garner, (comp.), 1972: 34.

45 NÉRET, 2007: 24.
} 
prendernos, ya que el fetichismo daliniano está fuertemente vinculado a la erótica de lo blando, y a la devoción por las muletas que sostienen materias blandas. Dalí llegaría incluso a confesar su fascinación por "la espalda blanda y rolliza de Hitler, siempre tan bien enfajada dentro de su uniforme" $"$. Lo cierto es que Dalí tenía "toda una teoría sobre lo "blando" y lo "duro", fundamento de su estética, que se resume en la fórmula: "vida perfecta de la morfología degenerada"" 47 . Adviértase también la tendencia del artista a representar formas blandas; desde El gran masturbador (1929) al Autorretrato blando con tocino frito (1941), pasando por los célebres relojes blandos de La persistencia de la memoria (1931), hasta composiciones como Araña de la tarde... esperanza (1940).

En este contexto, la imagen "caballo-mujer-león" ocupa un puesto relevante, pues es la única de la producción daliniana en la que, con carácter propio, se funden la articulación visual paranoico-crítica y la deformación de las sustancias blandas. Y es precisamente en la gestación de esta imagen que Buster Keaton interviene. Matthew Gale ha señalado muy inteligentemente la conexión de la imagen de Dalí con una escena de la película The Goat (La cabra, 1921), en la que Buster se monta a lomos de una estatua ecuestre provocando que las patas del caballo se deformen poco a poco bajo su peso; doblándose, casi derritiéndose. El regusto de lo blando y la morbidez de las formas presentes en esta escena, aplicados además a un caballo de curiosas similitudes formales con el caballo "múltiple" daliniano, hacen pensar en una evidente influencia ${ }^{48}$. Si escudriñamos la filmografía de Keaton, comprobaremos que la presencia de objetos sólidos que progresivamente van ablandándose es bastante frecuente, lo cual sin duda sería muy del gusto de Dalí. Destacaremos el sugerente estirador de caramelo de My wife's relations (Las relaciones de mi mujer, 1922), el catalejo de The boat, e incluso la soga de ahorcado y los barrotes de la prisión de Convict 13, que no dejan de mostrar ecos freudianos (figs. 3 y 4 ).

Aún así, la conexión Keaton-Freud no se entiende sin The Frozen North, una de las piezas más extrañas del cineasta. En esta película Keaton sorprende al espectador al comportarse como rufián, déspota egoísta, asesino, maltratador y violador. Pero hay una explicación: Buster se ha quedado dormido en el cine, y todo es producto de su mente vagando por el campo ilimitado del sueño. Un sueño que Freud clasificaría entre los "sueños manifiestamente inmorales", es decir, aquellos que son "expresiones de impulsos inmorales, incestuosos y perversos, o de deseos homicidas y sádi$\cos ^{\prime \prime 49}$. Claro está que esto no queda lejos de los deseos de libertad de los surrealistas. Como diría Breton: "El espíritu del hombre que sueña queda plenamente satisfecho con lo que sueña. [...]. Mata, vuela más de prisa, ama cuanto quieras. [...]. Déjate llevar, los acontecimientos no toleran que los difieras. Careces de nombre. Todo es de una facilidad preciosa" ${ }^{\circ 0}$.

En este ambiente se mueve Buñuel, motivado por la liberación que ofrece la simbiosis sueñoerótica-violencia. Y así, mientras que a Dalí le obsesiona el fetichismo de lo blando, a Buñuel el de la agresión y fragmentación corporal. Según explica Freud, el fetichista toma una parte del cuerpo como sustitutivo del objeto sexual, y se recrea en ella. No extraña entonces que el fetichismo así entendido conduzca a Buñuel a la mutilación corporal, tan propia de su cinematografía, o al

46 NÉRET, 2007: 60.

47 NÉRET, 2007: 27-8.

${ }^{48}$ Considérese también la pasión de Dalí por sustancias blandas como la cera (Dalí describe El gran masturbador como una 'gran cabeza, lívida y como de cera...' NérET, 2007: 27), empleada además en la fabricación de maniquíes, que fascinaban a Dalí, tal y como evidencia en su Taxi lluvioso y expresa en su San Sebastián y en la historia El maniquí de la nariz de azúcar, que relata e interpreta psicoanalíticamente en su Vida secreta. Fácil de derretir, este dúctil material simulaba la muerte y deformación de la carne. Dicho gusto por los maniquíes de cera lo compartía el pintor con su amigo Buñuel, que lo inmortalizó en Ensayo de un crimen.

${ }^{49}$ FreUd, 2005: 13.

${ }^{50}$ BRETON, 2002: 23. 


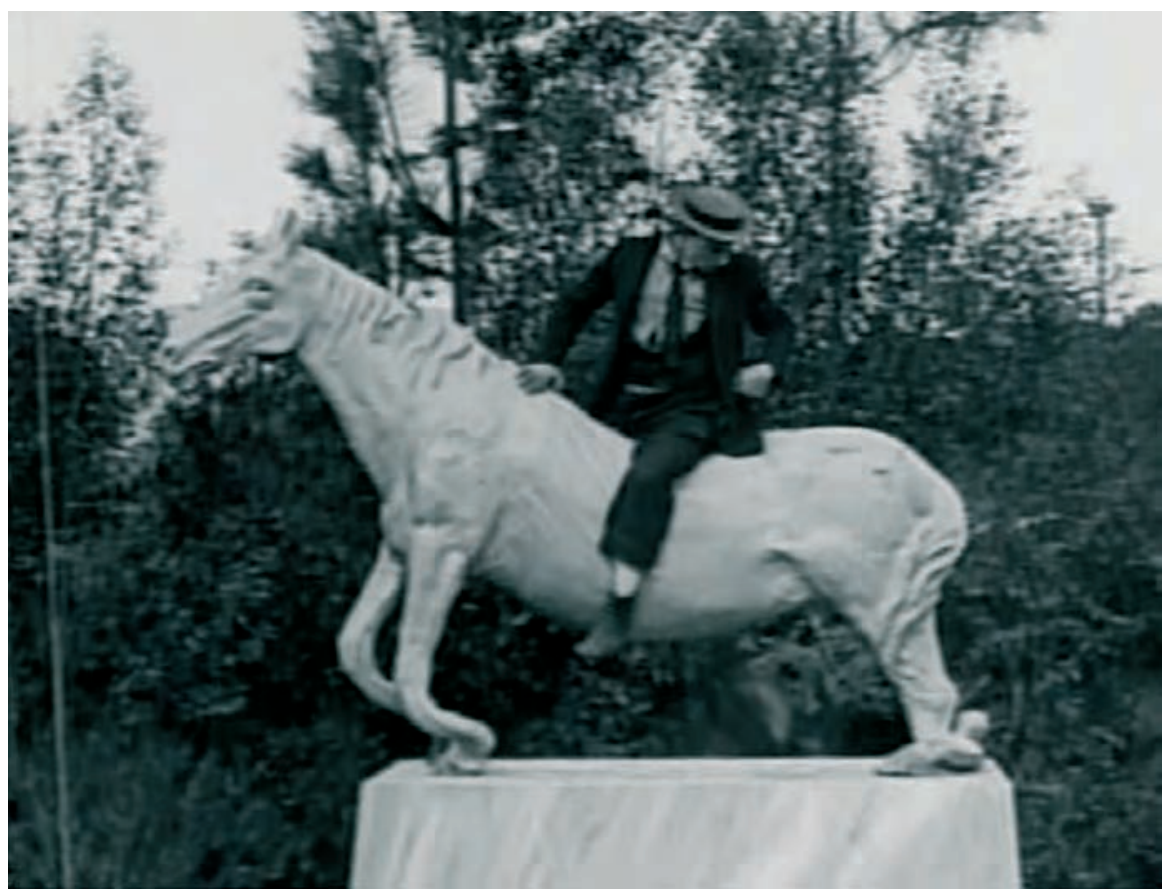

Fig. 3. Buster y el caballo blando en The Goat (La cabra, 1921).

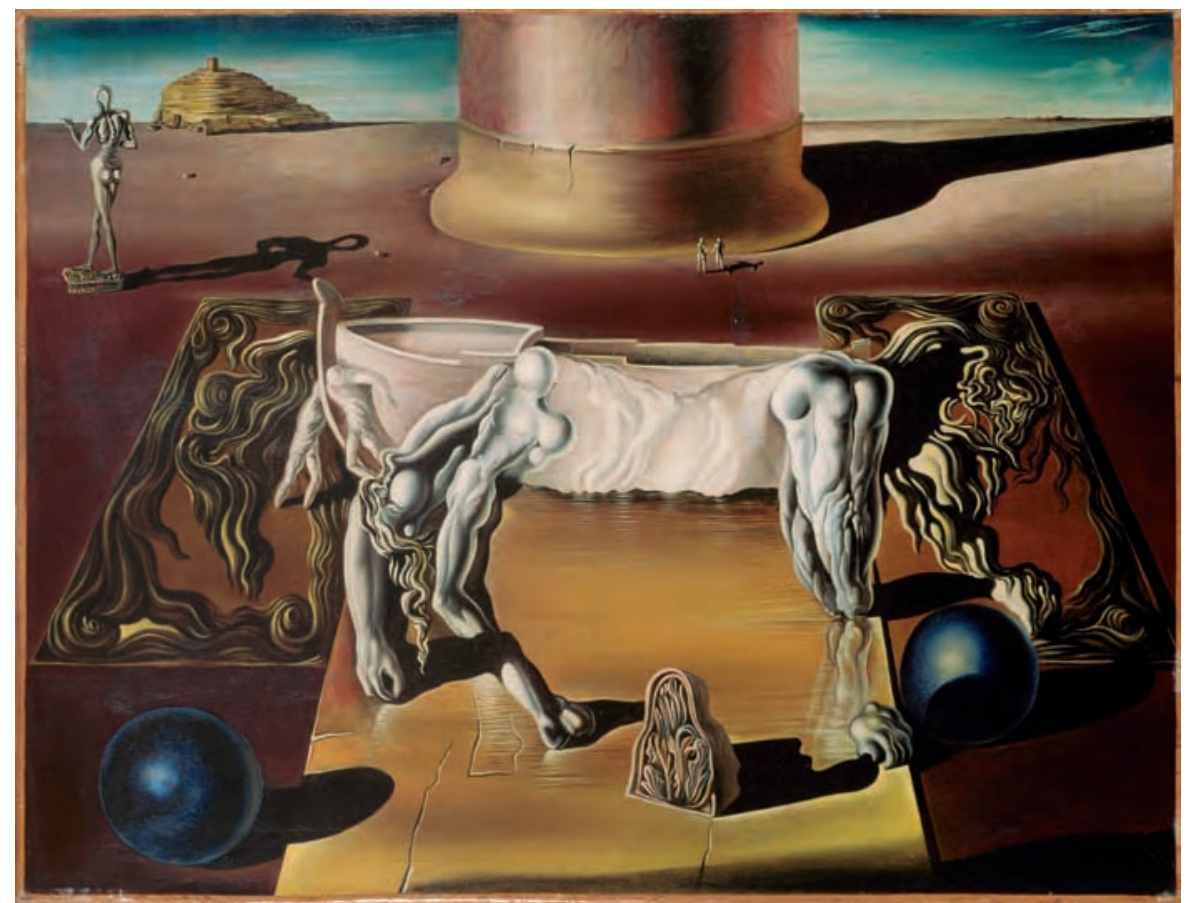

Fig. 4. Dalí: Mujer invisible dormida, caballo y león (1930).

Arch. esp. arte, LXXXVI, 341, ENERO-MARZO 2013, 29-48, ISSN: 0004-0428 
interés desmedido que confiere a determinadas partes anatómicas, caso de las piernas femeninas (Tristana, Viridiana, Ensayo de un crimen, Simón del desierto, etc.). Cabe aquí preguntarse si existen también estos rasgos fetichistas en Keaton. Para resolverlo, nos centraremos en una de las películas que Buster Keaton hace con Arbuckle. Se trata de Goodnight, nurse!, en la que curiosamente abundan las piernas seccionadas, pero que interesa sobre todo por una escena: la del "diálogo erótico" de Buster con Fatty, disfrazado éste último de enfermera, en donde el flirteo consiste en la imitación juguetona de meterse los dedos en la boca, hasta el extremo de que Buster llega a engullir casi toda su mano. Resulta interesante señalar la semejanza de esta situación con la que Buñuel propicia en La Edad de Oro (1930) -reinterpretando un boceto que le envía Dalí-, en la que los amantes demuestran su deseo mutuo metiéndose en la boca sus respectivas manos, lo que finaliza casi en canibalismo, al amputarse los dedos ${ }^{51}$
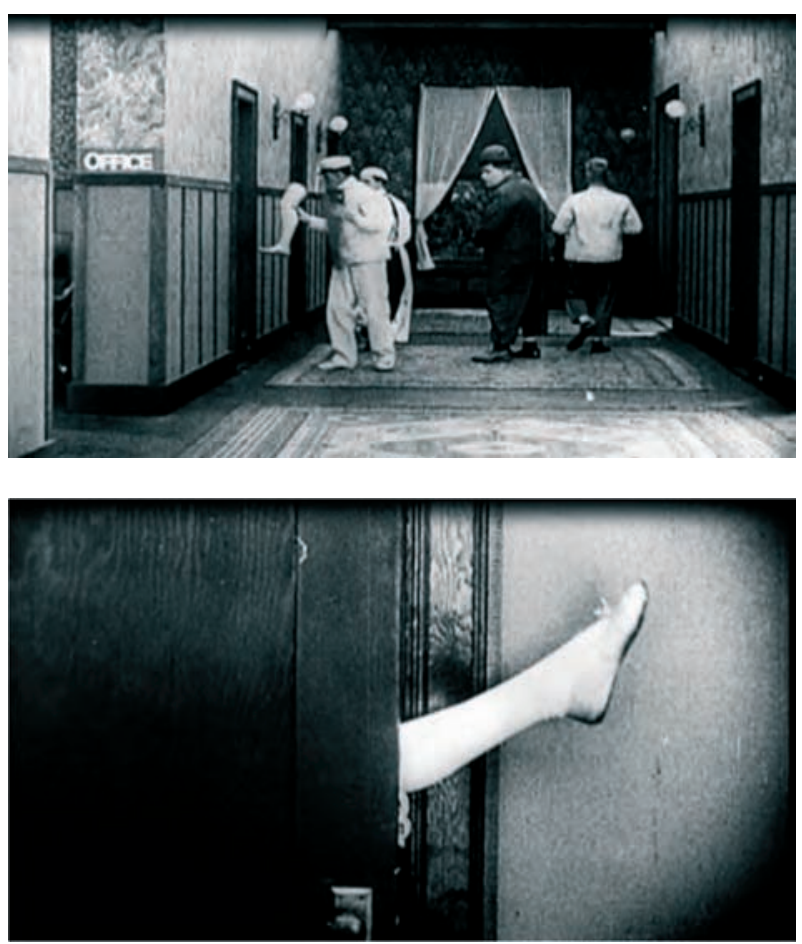

Figs. 5, 6. Piernas seccionadas en Goodnight nurse! (;Buenas noches, enfermera!, 1918). (figs. 5 a 10).

El valor de la boca como zona erógena, junto con la práctica de meterse los dedos en la boca, ha sido remarcado por Freud en relación a la sexualidad infantil y las fases de lactancia y "chupeteo", lo cual está fuertemente vinculado al sentido del fetiche en la vida adulta, y puede ser extrapolado a otras partes corporales semejantes: "Una parte de los mismos labios, la lengua o cualquier otro punto asequible de la piel del mismo individuo (a veces hasta el dedo gordo de un pie), son tomados como objeto de la succión" 52 (figs. 11 a 14).

Esto figura también en La Edad de Oro, cuando en ausencia de su amante, e indudablemente a modo de sustitución compensatoria, la mujer chupa el dedo gordo del pie de una escultura clásica $^{53}$.

\footnotetext{
${ }^{51}$ Irónicamente, la mutilación de los dedos está también presente en Buster Keaton, pero no en la ficción cinematográfica sino en su propia biografía. Recordando su infancia, relata Keaton: 'Aquella precisa mañana yo estaba paseando por el patio trasero de la pensión en la que nos hospedábamos. La asistenta estaba escurriendo la ropa. La escurridora me fascinó y metí dentro mi dedo índice, espachurrándomelo tanto que el médico al que llamaron me cortó el dedo a la altura de la primera falange'. (Keaton, 2006: 22).

${ }^{52}$ FreUd, 1985: 55-6.

${ }^{53}$ La inclinación erótica por los pies es otro aspecto clave en Buñuel, que lo hace patente, por ejemplo, en la escena del lavatorio de los pies de Él. No se obvie tampoco la lectura fetichista del cuento de la Cenicienta, que tanto obsesionaba a los surrealistas. Breton, en El amor loco, confiesa haber encargado un cenicero en forma de zapatilla de Cenicienta a Giacometti, movido por un fuerte sentido erótico y una clara influencia freudiana. Breton era también conocedor del cuento original de Perrault, en el que las hermanastras se amputan los dedos del pie para que les quepa el zapatito de cristal (como también ocurre en la versión china del mito, protagonizado por una Cenicienta de pies diminutos llamada "Pies de Loto"). Una mezcla de fetichismo y sadismo que entronca claramente con Freud y Buñuel.
} 

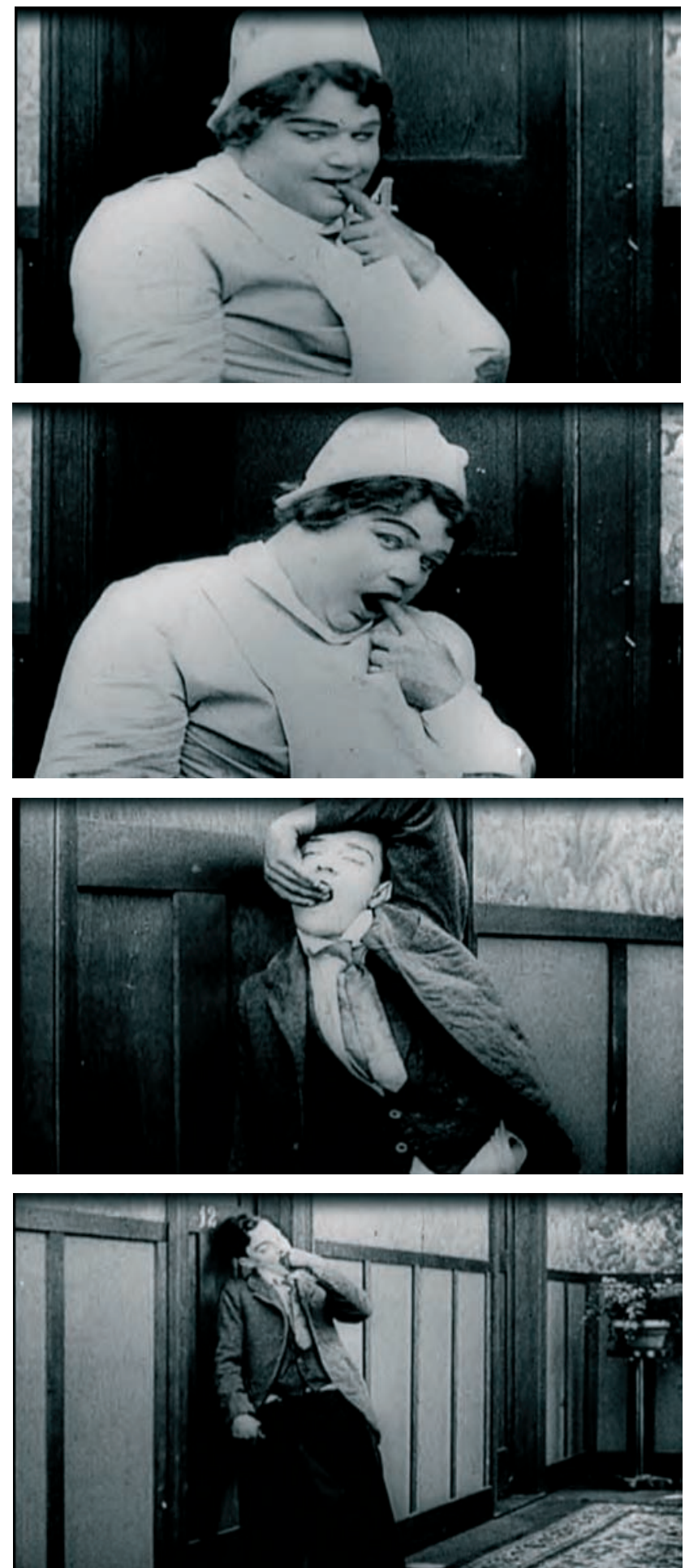

Figs. 7, 8, 9, 10. Escena de Goodnight nurse! (;Buenas noches, enfermera!, 1918).

Arch. esp. arte, LXXXVI, 341, ENERO-MARZO 2013, 29-48, ISSN: 0004-0428 


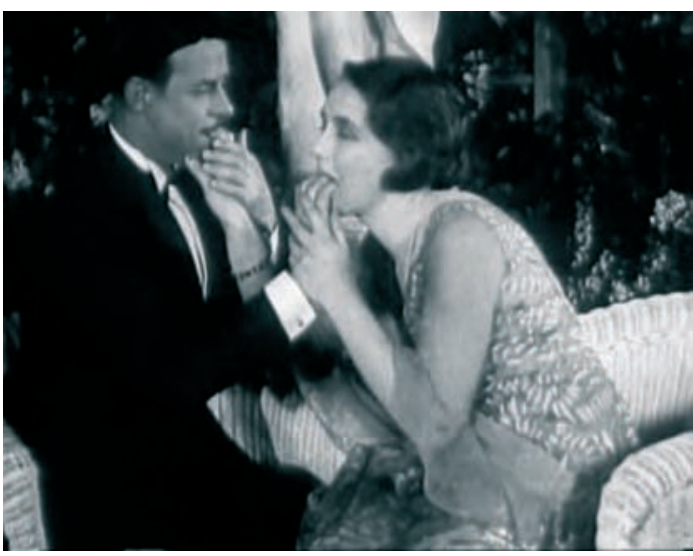

Fig. 11. El fetichismo de dedos y boca en La Edad de Oro (1930).

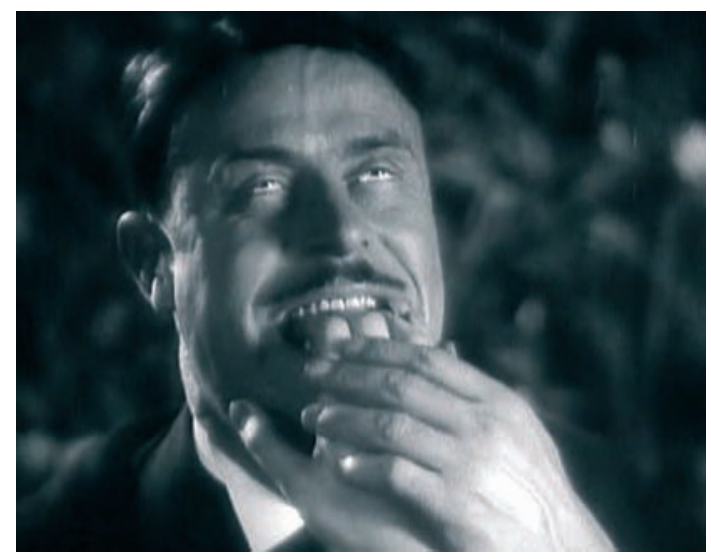

Fig. 12. Fotograma de La Edad de Oro (1930).

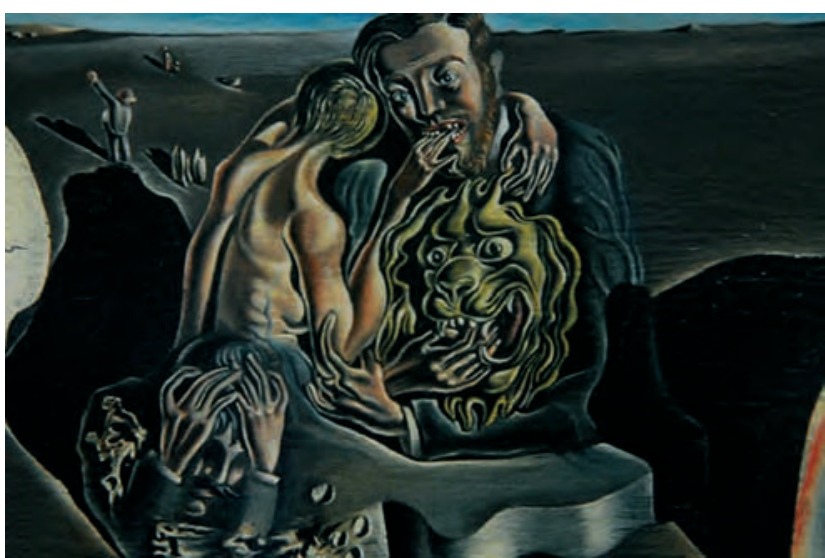

Fig. 13. Dalí: Detalle de La adecuación del deseo. (1929).

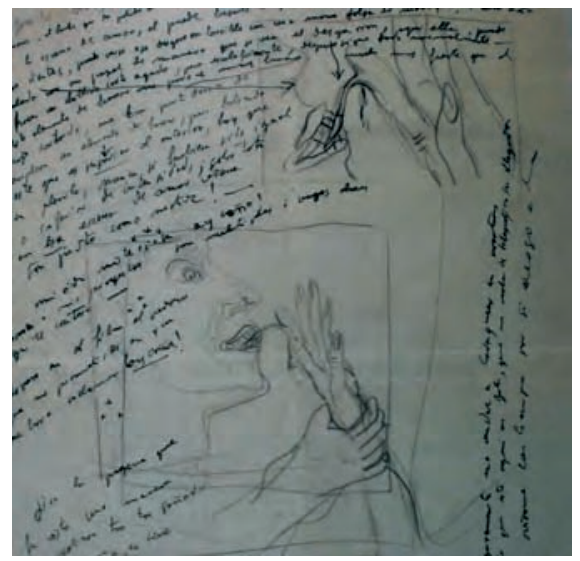

Fig. 14. Carta de Dalí a Buñuel especificando ideas para La Edad de Oro.

Aquí de nuevo pulula Dalí, en concreto en lo referente a su reiterativa obsesión por el erotismo de las esculturas clásicas, sobre todo de la Venus de Milo; estatua que casualmente aparece en algunos cortos de Keaton, como My wife's relations, y que el propio cineasta emuló en algunas fotografías publicitarias de su película The college (El colegial, 1927), film que entusiasmó a los amigos de la Residencia y especialmente a Buñuel, que escribiría con tal motivo su conocido artículo Contra toda infección sentimental para Cahiers d'Art. Otros artistas imbuidos en la atmósfera surrealista, como Jean Cocteau, tampoco quedarían al margen de la influencia de esta escultura mítica, demostrándolo ejemplarmente en Sangre de Poeta (1930) (figs. 15 a 17).

\section{Un paseo en bicicleta}

Para concluir el recorrido por las conexiones de Keaton con los surrealistas de la Residencia de Estudiantes, queda apuntalar un aspecto alusivo al fetiche de índole objetual. Nos referimos en 


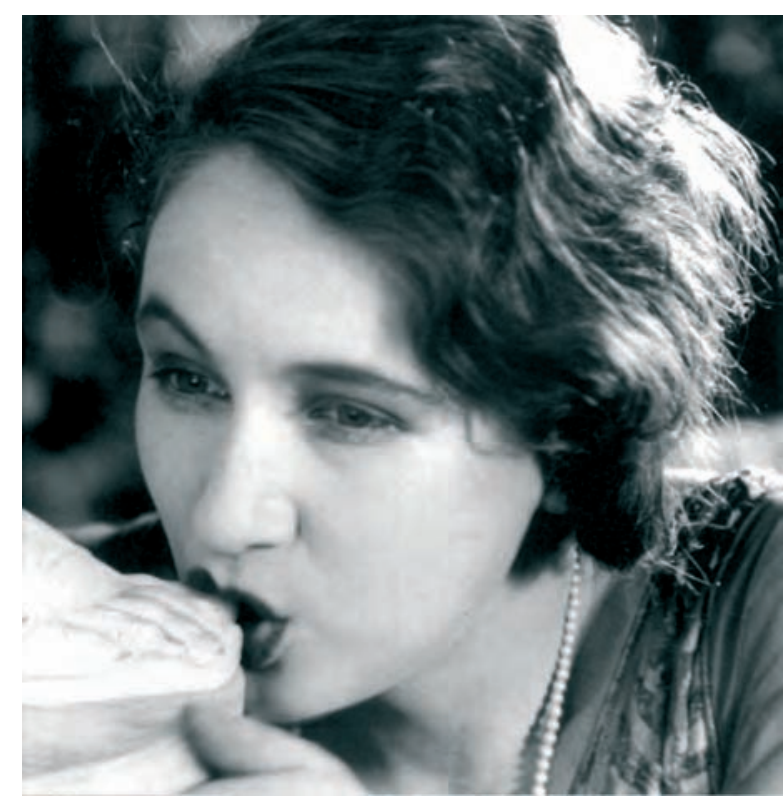

Fig. 15. El pie de la estatua clásica en La Edad de Oro (1930).

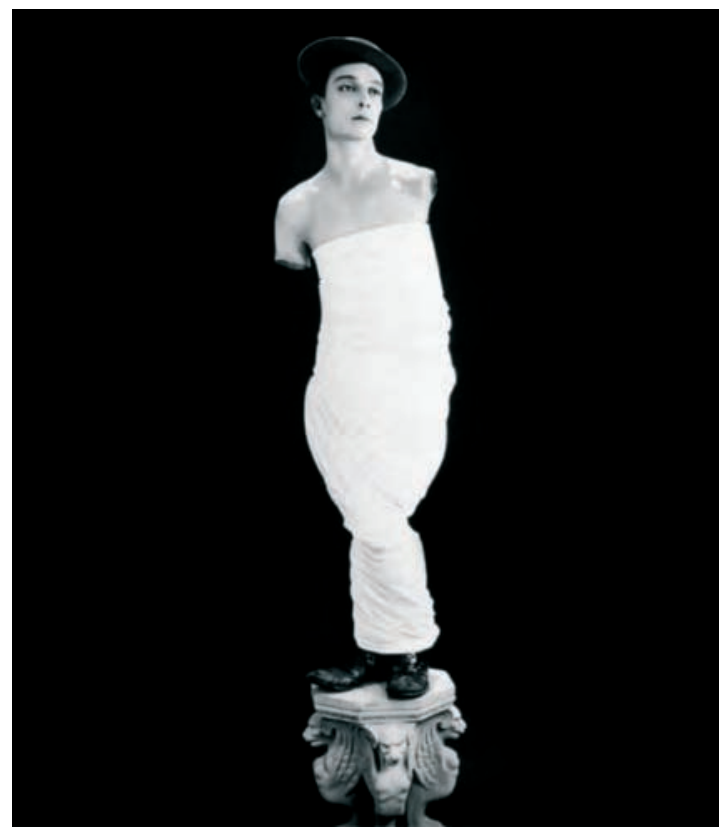

Fig. 16. Keaton como Venus clásica en una fotografía publicitaria de The college (El colegial, 1927). concreto a la bicicleta, objeto que capta la atención erótica de Buñuel, Dalí, y sobre todo de Lorca, y que relacionan estrechamente con Buster Keaton. Así lo demuestra el poeta en Diálogo de la bicicleta en Filadelfia, finalmente titulado El paseo de Buster Keaton (1927-8). En esta obrita, Lorca capta la pureza de carácter del personaje de Keaton, su naturaleza onírica y cierto aire andrógino, y lo incorpora a su personal universo identitario para a través de esta figura keatoniana canalizar sus angustias homosexuales y su profunda melancolía. Así, el Buster Keaton de Lorca sale a pasear en bicicleta por los campos de Filadelfia, suspirando por un amor imposible y manifestando su frustrado deseo de ser un cisne. "Sus ojos infinitos y tristes como los de una bestia recién nacida, sueñan lirios, ángeles y cinturones de seda" ${ }^{\circ 4}$. Esta visión de Buster Keaton la comparte Lorca con Dalí, a quien manda una carta

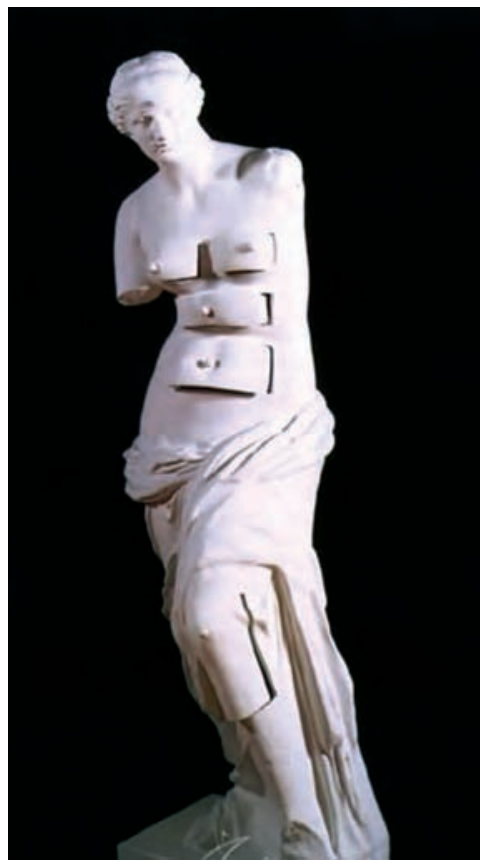

Fig. 17. Dalí: Venus de los cajones (1936).

\footnotetext{
${ }^{54}$ Lorca en Hernández Pin, SÁnchez, (coord.), 2009: 204.
} 
en la que incluye el Paseo, y en la que se despide diciendo:

Este diálogo conseguido con tan pobres elementos me da una preciosa impresión de Buster Kiton. ¿Y a tí Hijitito? ${ }^{55}$. obra $^{56}$.

Obviamente, a Dalí le fascinó la

Protagonista incuestionable en este Paseo es la bicicleta, tan pura e ingenua como la personalidad de su dueño. Según Lorca, se trata de "una bicicleta como todas, pero la única empapada de inocencia. Adán y Eva correrían asustados si vieran un vaso lleno de agua, y acariciarían en cambio la bicicleta de Keaton" ${ }^{\text {"57 }}$. Ahora bien, no es ésta la única ocasión en la que se concierta un encuentro entre Buster Keaton y una bicicleta. De hecho, son varias, a la par que sugerentes, las ocasiones en las que Keaton aparece montando en bicicleta a lo largo de sus películas (como acertadamente estudia Amparo Martínez Herranz ${ }^{58}$ ); pero sin lugar a dudas la más ingenua de todas es la de Our hospitality (La ley de la hospitalidad, 1923) $)^{59}$, película para la que Keaton hizo fabricar expresamente una bicicleta basada en un diseño antiguo, con la cual logra una impronta ridículamente tierna y juvenil, en la que bien pudo inspirarse Lorca (figs. 18, 19).

Otros paseos en bicicleta aparecen The rough house (Tres pies al gato, 1917) y His wedding night (Noche de bodas, 1917), películas en las que el protagonista emplea el vehículo como instrumento de trabajo, pues es un reparti-

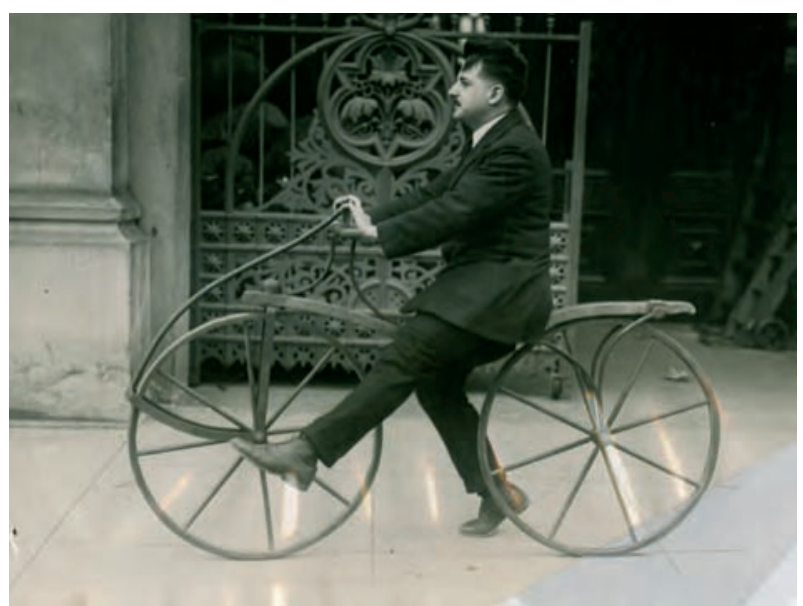

Fig. 18. Modelo de bicicleta construido expresamente para Buster Keaton.

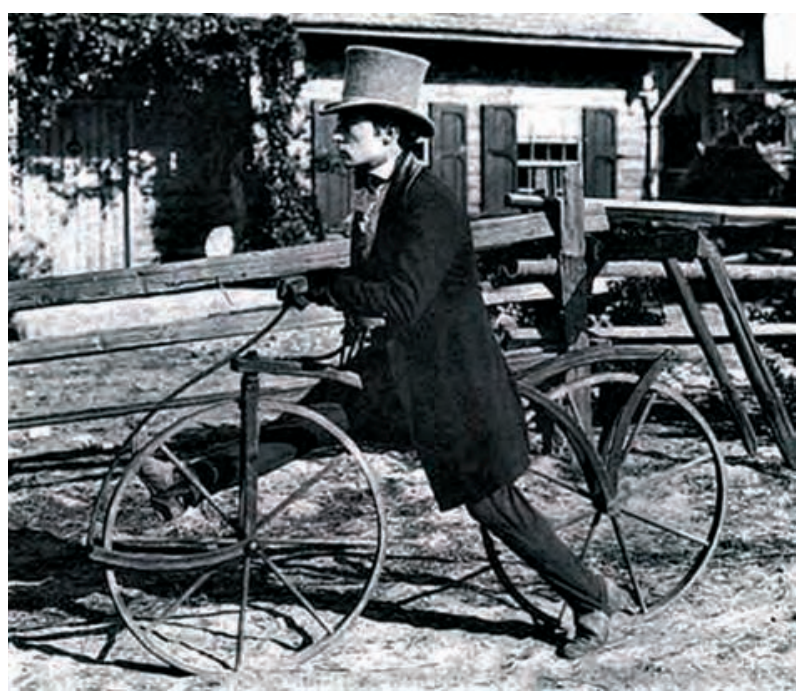

Fig. 19. Buster se pasea en bicicleta en Our hospitality (La ley de la hospitalidad, 1923).

${ }^{55}$ Gibson, 2000: 140.

${ }^{56}$ El recurso a la bicicleta en Dalí y Buñuel está también muy ligado a Keaton. Da ejemplar testimonio de ello la secuencia del ciclista al inicio de Un chien andalou, fuertemente inspirada en el lorquiano Paseo de Buster Keaton, como también la elección del propio actor para la película, Pierre Batcheff, decantada en cierta medida por su parecido físico con Keaton.

${ }^{57}$ Lorca en Hernández Pin, SÁnchez, (coord.), 2009: 203-4

58 Martínez Herranz en Hernández Pin, SÁnchez, (coord.), 2009: 95-111.

${ }^{59}$ La película se estrenó en Madrid el 15 de diciembre de 1924 en los cines Real Cinema y Príncipe Alfonso. 


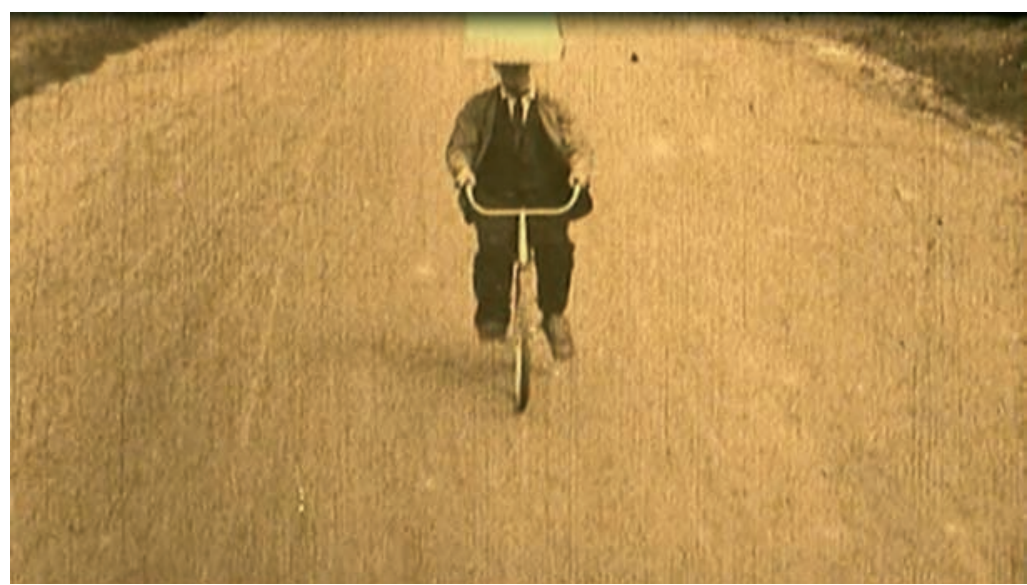

Fig. 20. El repartidor entrega el vestido de novia en His wedding night (Noche de bodas, 1917)

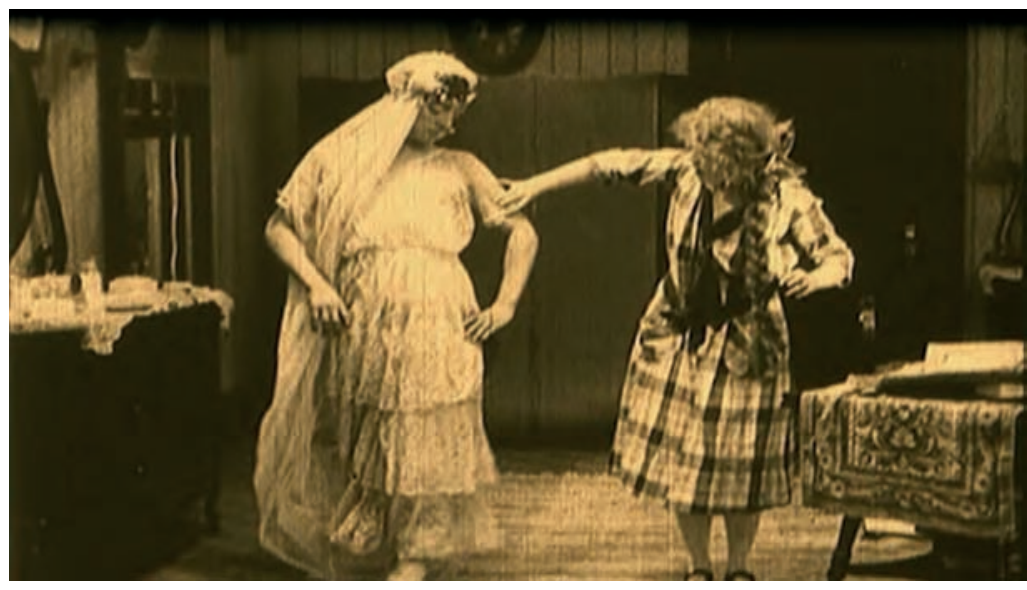

Fig. 21. Buster se prueba el traje de novia en His wedding night (Noche de bodas, 1917).

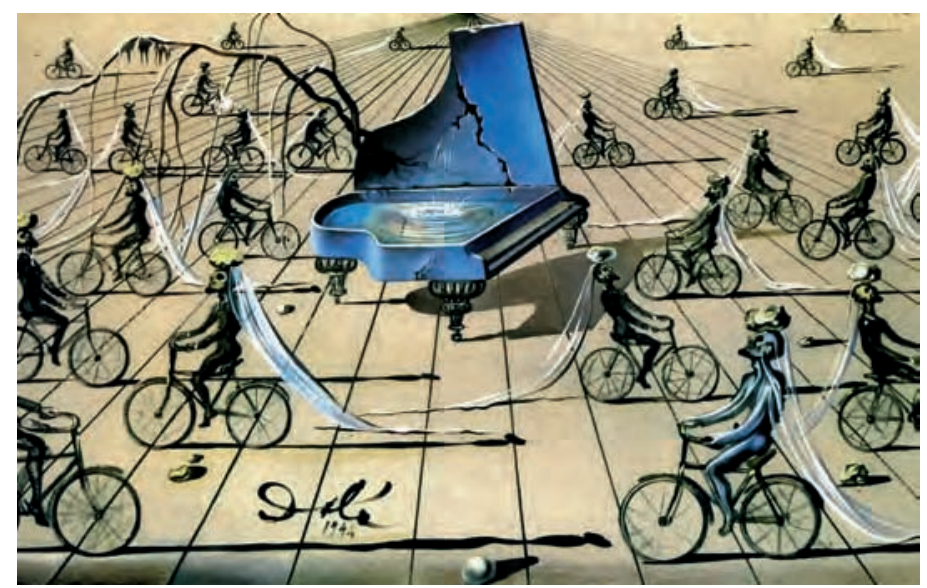

Fig. 22. Dalí: Coloquio sentimental (1938).

Arch. esp. arte, LXXXVI, 341, ENERO-MARZO 2013, 29-48, ISSN: 0004-0428 
dor. Por ejemplo, en la segunda de las películas citadas, Keaton tiene que hacer entrega a domicilio de un vestido de novia, pero como necesita ambas manos para conducir la bicicleta, no tiene más remedio que colocar el paquete sobre su cabeza. Esta imagen mantiene fuertes vínculos con otra muy repetitiva de la iconografía daliniana, presente en obras como Placeres iluminados (1929), Coloquio sentimental (1948), y en proyectos cinematográficos como Babaouo (1932) o la irrealizada película con los hermanos Marx: la del ciclista que porta un bulto sobre la cabeza y que a veces lleva también un largo velo blanco que recuerda al tocado de una novia. Las similitudes con el film de Keaton se evidencian aún más si se observa que una vez entregado el vestido, la compradora obliga a Buster a probárselo para comprobar que todo está correcto, de forma que el espectador asiste a una curiosa demostración de travestismo de Keaton, el ciclista repartidor, disfrazado de novia y adornado con un largo velo (figs. 20 a 22).

\section{BIBLIOGRAFÍA}

Breton, André, El amor loco. Alianza. Madrid. 2000.

Breton, André, Manifiestos del surrealismo. Visor Libros. Madrid. 2002.

Breton, André, y Eluard, Paul, Diccionario abreviado del surrealismo. Siruela. Madrid. 2003.

Buñuel, Luis, Mi último suspiro. Plaza \& Janes. Barcelona. 1982.

Dalí, Salvador, Obra completa. Vol. I. Textos Autobiográficos 1: Un diario (1919-1920); La vida secreta de Salvador Dali; Diario de un genio. Ediciones Destino. Fundació Gala-Salvador Dalí. Sociedad Estatal de Conmemoraciones Culturales. Barcelona. 2003.

De la Cueva, Almudena (asesora de la edición), Ola Pepín! Dalí, Lorca y Buñuel en la

Residencia de Estudiantes. Publicaciones de la Residencia de Estudiantes; Fundació Caixa Catalunya; Fundació Gala-Salvador Dalí. Madrid. 2007.

Felten, Uta, "La recéption de Buster Keaton dans le surréalisme espagnol". Le Cinéma des Surréalistes. Étudeds rénies par Henri Bébar. Mélusine. Cahiers du Centre de Recherche sur le Surréalisme. No. 24, 2004. Pp. 171-181.

Freud, Sigmund, Esquema del psicoanálisis. Paidós. Buenos Aires. 1966.

Freud, Sigmund, Compendio del psicoanálisis. Tecnos. Madrid. 1985.

Freud, Sigmund, Tres ensayos sobre teoría sexual. EL PAÍS. Editorial Biblioteca Nueva. Madrid. 2002.

Freud, Sigmund, Nuevas aportaciones a la interpretación de los sueños. Biblioteca Freud. Alianza. Madrid. 2005.

Gale, Matthew (editor), Dalí \& Film. Tate Publishing. Londres. 2007.

Gibson, Ian, Lorca-Dali, el amor que no pudo ser. Plaza \& Janés. Barcelona. 2000.

Gubern, Román, Proyector de luna. La generación del 27 y el cine. Anagrama. Barcelona. 1999.

Hernández Pin, Yolanda, y Sánchez, Pilar (coordinadoras), Un perro andaluz ochenta años después. Biblioteca BlowUp Libros Únicos. La Fábrica; Sociedad Estatal de Conmemoraciones Culturales. Madrid. 2009.

Keaton, Buster, Slapstick. (Memorias en colaboración con Charles Samuels). Blanco y Negro. Plot Ediciones. Madrid. 2006.

Lastra, James, "Buñuel, Bataille, and Buster, or, the surrealist life of things". Critical Quarterly. Vol. 51. No. 2, 2009. Pp. 16-38.

Minguet, Joan M., Buster Keaton. Cátedra. Madrid. 2008.

Néret, Gilles, Dalí. Taschen. Madrid. 2007.

Oliver, Jos, y Garner, José Luis (compiladores), Buster Keaton contra la infección sentimental. Anagrama. Barcelona. 1972.

Oms, Marcel, Buster Keaton. Tusquets. Barcelona. 1969.

Poyato Sánchez, Pedro, Las imágenes cinematográficas de Luis Buñuel. (Fotografias que se suceden vermicularmente). Un perro andaluz, Viridiana, Ese oscuro objeto del deseo: ejercicios de análisis textual. Caja España. Valladolid. 1998.

Arch. esp. arte, LXXXVI, 341, ENERO-MARZO 2013, 29-48, ISSN: 0004-0428 
Poyato Sánchez, Pedro, Introducción a la teoría y análisis de la imagen fo-cinemato-gráfica. Grupo Editorial Universitario. Granada. 2006.

Puelles Romero, Luis, El desorden necesario. Filosofía del objeto surrealista. Universidad de Málaga. 2002. Ramírez, Juan Antonio, Dalí: lo crudo y lo podrido. La Balsa de Medusa, 124. Antonio Machado Libros. Madrid. 2002.

Sánchez Vidal, Agustín, Buñuel, Lorca, Dalí: El enigma sin fin. Planeta. Barcelona. 2009.

Santos Torroella, Rafael, Dalí residente. Publicaciones de la Residencia de Estudiantes; Consejo Superior de Investigaciones Científicas. Madrid. 1992.

Tranströmer, Tomas, "La poesía es algo parecido a un sueño en la vigilia". Entrevista de J. Antonio González Iglesias. Vida \& Artes. Cultura. EL PAIS. 7 de Octubre de 2011, pp. 44-5.

http://hemeroteca.abc.es/nav/Navigate.exe/hemeroteca.

Fecha de recepción: 25-XI-2011

Fecha de aceptación: 27-II-2012 